\title{
The effect of temperature and type of peroxide on graphene synthesized by improved Hummers' method
}

\author{
Negar Z. Khatmi Maab ${ }^{1} \cdot$ Ali Shokuhfar ${ }^{1} \cdot$ Shervin Ahmadi $^{2}$
}

Received: 29 March 2016/ Accepted: 19 May 2016/Published online: 21 October 2016

(c) The Author(s) 2016. This article is published with open access at Springerlink.com

\begin{abstract}
The effects of temperature and the type of peroxide used in improved Hummers' method for synthesis of graphene oxide were investigated. Two different temperatures of 60 and $75{ }^{\circ} \mathrm{C}$ were examined and the performance of $\mathrm{H}_{2} \mathrm{O}_{2}$ and 2,5-bis(tert-butylperoxy)-2,5-dimethylhexane as peroxides was compared. Scanning electron microscope, fourier transform infrared spectroscopy, UV-vis absorption, Raman, and X-ray diffraction were utilized to characterize the properties of the as-prepared graphene samples. The results of this study revealed that the temperature is of the most importance in the synthesis process.
\end{abstract}

Keywords Graphene · Hummers' method · Raman · XRD · FTIR

\section{Introduction}

Graphene, as flat monolayer of carbon atoms tightly packed into a two-dimensional hexagonal structure [1], exhibits extraordinary characteristics, such as high Young's modulus (about $10^{7}$ bar), large specific surface area $\left(2.63 \mathrm{~m}^{2} \mathrm{mg}^{-1}\right)$, high thermal conductivity (about $\left.50 \mathrm{~W} \mathrm{~cm}^{-1} \mathrm{~K}^{-1}\right)$, high intrinsic mobility $\left(20 \mathrm{~m}^{2} \mathrm{vs}^{-1}\right)$, high thermal conductivity (about $5000 \mathrm{Wm}^{-1} \mathrm{~K}^{-1}$ ), good electrical conductivity and optical transmittance (about $97.7 \%$ ) [1-6]. Due to these properties, it is widely used in

Ali Shokuhfar

shokuhfar@kntu.ac.ir

1 Department of Materials Engineering, Karaj Branch, Islamic Azad University, Karaj, Iran

2 Iran Polymer and Petrochemical Institute, P.O. Box 14975/112, Tehran, Iran applications such as supercapacitors and transparent conductive electrodes for dye-sensitized solar [7, 8]. It has been also used for applications in electronics [9], catalysis [10], sensors [11], and energy conversion/storage [12, 13]. Therefore, economical mass production of graphene materials is of significant importance.

There are several methods to synthesize graphene, which includes CVD (chemical vapor deposition) [14], optimized micromechanical cleavage of graphite [15], and microexfoliation of graphite [16]. Graphite is more accessible and cheaper in comparison to graphene and its structure is consisted of many flat layers of graphene. To achieve graphene sheets, exfoliation of their stacked form (e.g., by highly oxidants) is needed [17].

In this study, the effect of temperature and the type of peroxide on graphene synthesized by improved Hummers' method were investigated. Chemical exfoliation of graphite was performed in a two-step process to obtain graphene from graphite. The first step is oxidation of graphite to graphene oxide (GO) and the second step subsequent reduction of GO to graphene. Different temperatures of 60 and $75^{\circ} \mathrm{C}$ were examined and two types of peroxides $\left[\mathrm{H}_{2} \mathrm{O}_{2}\right.$ and 2,5-bis(tert-butylperoxy)-2,5-dimethylhexane] were used. The characteristic differences of the obtained samples were studied by scanning electron microscope (SEM), fourier transform infrared spectroscopy (FT-IR), UV-vis absorption, Raman, and XRD.

\section{Experimental}

\section{Materials and instruments}

Graphite powder, $98 \% \mathrm{H}_{2} \mathrm{SO}_{4}, 30 \% \mathrm{H}_{2} \mathrm{O}_{2}$ aqueous solution, and $\mathrm{HNO}_{3}$ were purchased from Merck Ltd., 
Germany and $\mathrm{KMnO}_{4}$ was bought from Sigma-Aldrich (USA). The infrared spectra were obtained using a spectrum 400 FT-IR spectrometer (Perkin Elmer). The structure and d-spacing of samples were analyzed by an X-ray diffractometer (Siemens D5000). SEM images were taken by Philips (X130); the UV-vis spectra were obtained using a UV-vis spectrophotometer Shimadzu (UV-160 A).

\section{Synthesis of GO}

GO was produced from graphite powder via Hummer's method. $1 \mathrm{~g}$ graphite powder and $1 \mathrm{~g} \mathrm{NaNO}_{3}$ were mixed by the addition of $35 \mathrm{~mL} \mathrm{H}_{2} \mathrm{SO}_{4}$ and $15 \mathrm{~mL} \mathrm{HNO}_{3}$ at $25{ }^{\circ} \mathrm{C}$. Using an ice bath, the mixture was cooled to $5{ }^{\circ} \mathrm{C}$ (to prevent overheating and explosion) while being stirred. Then, $6 \mathrm{~g} \mathrm{KMnO}_{4}$ was added gradually to the solution. The temperature was kept less than $20^{\circ} \mathrm{C}$ for $10 \mathrm{~min}$. After that, the mixture was stirred at different heating temperatures of 60 and $75{ }^{\circ} \mathrm{C}$ for $2 \mathrm{~h}$ and the obtained solution was diluted by adding deionized water to $100 \mathrm{~mL}$. To ensure complete reaction with $\mathrm{KMnO}_{4}$, the suspension was further treated with $200 \mathrm{~mL}$ of $\mathrm{H}_{2} \mathrm{O}$ (water) containing $6 \mathrm{~mL}$ hydrogen peroxide [the effects of $30 \% \mathrm{H}_{2} \mathrm{O}_{2}$ solution and 2,5-bis(tert-butylperoxy)-2,5-dimethylhexane were investigated]. Finally, the suspension was centrifuged several times for removal of the remaining acids and salts. To extract graphene, the suspension was sonicated for $30 \mathrm{~min}$. GO sheets were thus obtained. Then, the GO suspension evaporated and dried for $24 \mathrm{~h}$ at room temperature (Table 1).

\section{Synthesis of graphene from GO}

To obtain reduced graphene, the GO was treated thermally, while it was placed into a furnace with a crucible at $900{ }^{\circ} \mathrm{C}$ for 30 min under the flow of $\mathrm{N}_{2}$ gas.

\section{Results and discussion}

Synthesis of GO via Hummer's method, including graphite in concentrated acid (for example $\mathrm{HNO}_{3}$ ) in the existence of oxidant, demonstrated a safer and productive method for graphite oxidation. Modified Hummer's method is the best method used for the oxidation of graphite $[18,19]$.
XRD patterns of graphite (G), G60H, G60L, and G75L are presented in Fig. 1. The intense (002) peak of $\mathrm{G}$ is obvious around $2 \theta=26^{\circ}$ with a $d$-spacing of $3.39 \AA$. In $\mathrm{G} 60 \mathrm{H}$, this peak has shifted to $2 \theta=28^{\circ}$ corresponding to the layer structure with the distance between interlayer of $3.49 \AA$. The increase in the temperature has altered the position of the peaks. In G60L, the peak occurs around $2 \theta=28^{\circ}$ with an interlayer distance of $3.45 \AA$. Compared with the interlayer distance of graphite refers to synthesis of graphene. The shift also implies the presence of some residual functional groups and defects [20]. The intense (002) peak of G75L is seen around $2 \theta=26^{\circ}$.

The UV-visible of G60H and G60L is shown in Fig. 2. According to the absorbance spectra, samples have a broad peak between 200 and $250 \mathrm{~nm}$ which are attributed to $\pi-\pi^{*}$ transition, due to $\mathrm{sp}^{2}$ hybridization of carbon particles [21]. No significant difference could be found between the two samples concluding the unimportance of the type of used peroxide in the last step of chemical exfoliation.

The FTIR spectrum of G60L (Fig. 3b) shows a peak at $3400 \mathrm{~cm}^{-1}$ corresponding to the stretching modes of hydroxyl groups. The absorption peaks at 2920 and $2850 \mathrm{~cm}^{-1}$ are represented the stretching modes $\mathrm{C}-\mathrm{H}$. While the presence of two absorption peaks observed at 1110 and $1630 \mathrm{~cm}^{-1}$ can be attributed to the stretching mode of the carbon-oxygen bonds and aromatic vibrations of $\mathrm{C}=\mathrm{C}$. In addition, peaks were proposed in G60L, GO60H (Fig. 3c) also have a peak at $1380 \mathrm{~cm}^{-1}$, this peak relates to $\mathrm{COH}$ [22].

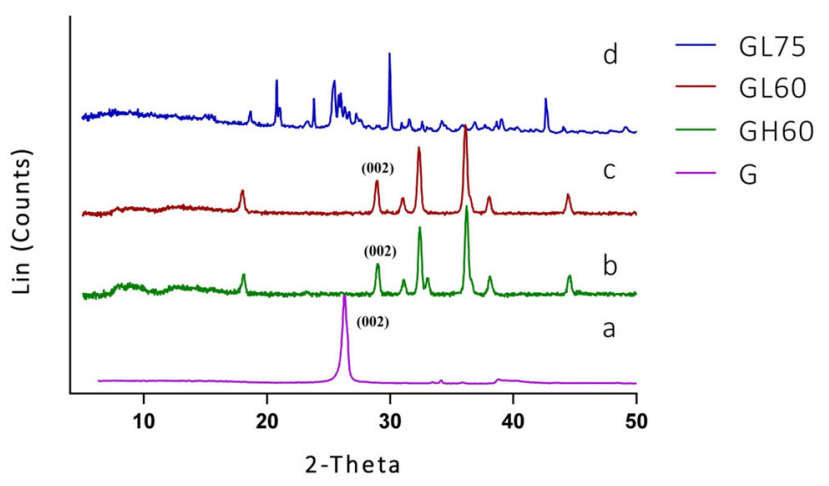

Fig. 1 The XRD pattern of a G, b GH60, c GL60, d GL75
Table 1 Summarizes the synthesis parameters of the samples

\begin{tabular}{lll}
\hline Sample & Heating temp. $\left({ }^{\circ} \mathrm{C}\right)$ & Used peroxide \\
\hline G60H & 60 & $\mathrm{H}_{2} \mathrm{O}_{2}$ \\
G60L & 60 & 2,5 -Bis(tert-butylperoxy)-2,5-dimethylhexane \\
G75L & 75 & 2,5 -Bis(tert-butylperoxy)-2,5-dimethylhexane \\
\hline
\end{tabular}



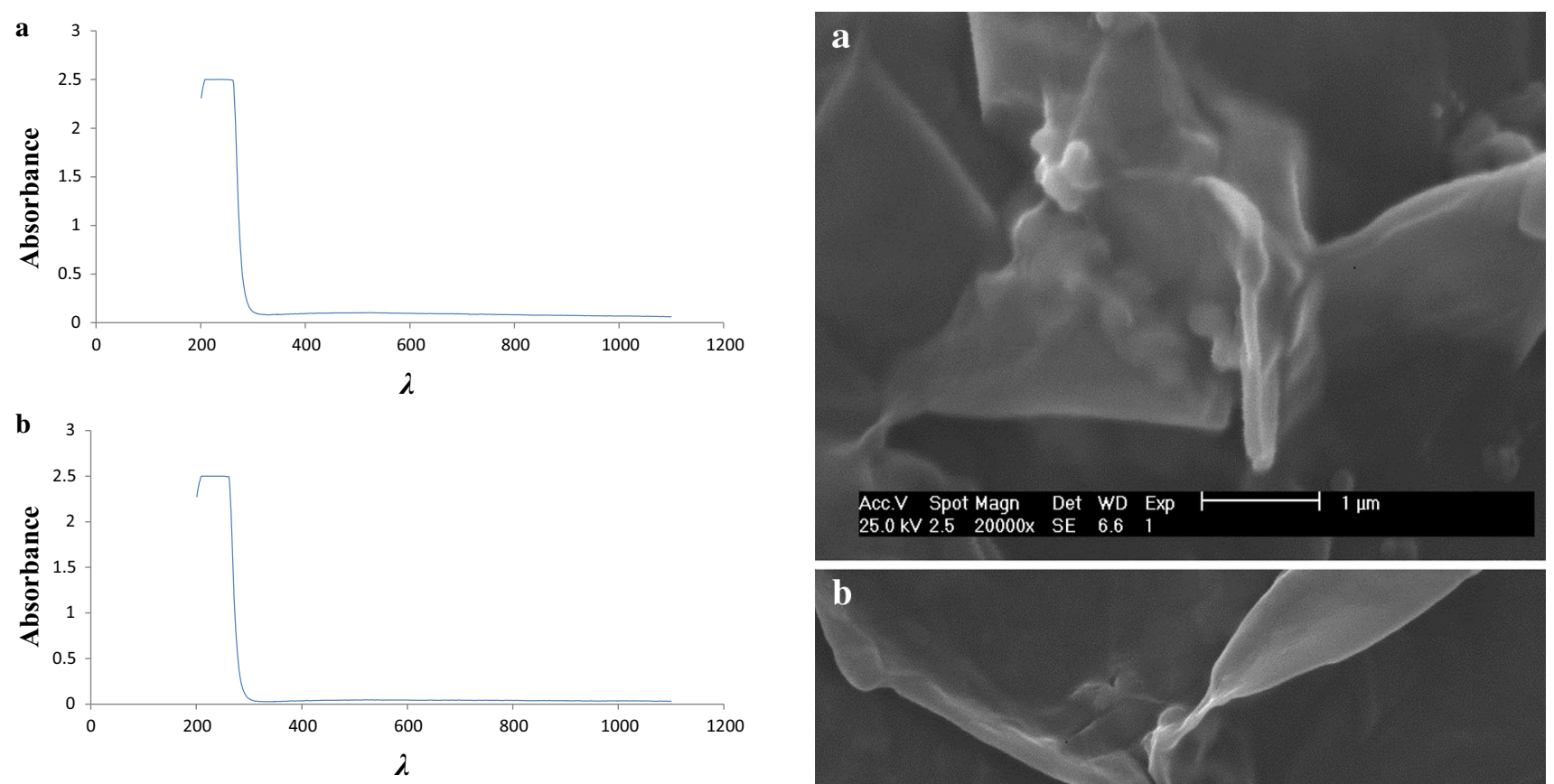

Fig. 2 a UV-vis absorbance of GH60. b UV-vis absorbance of GL60
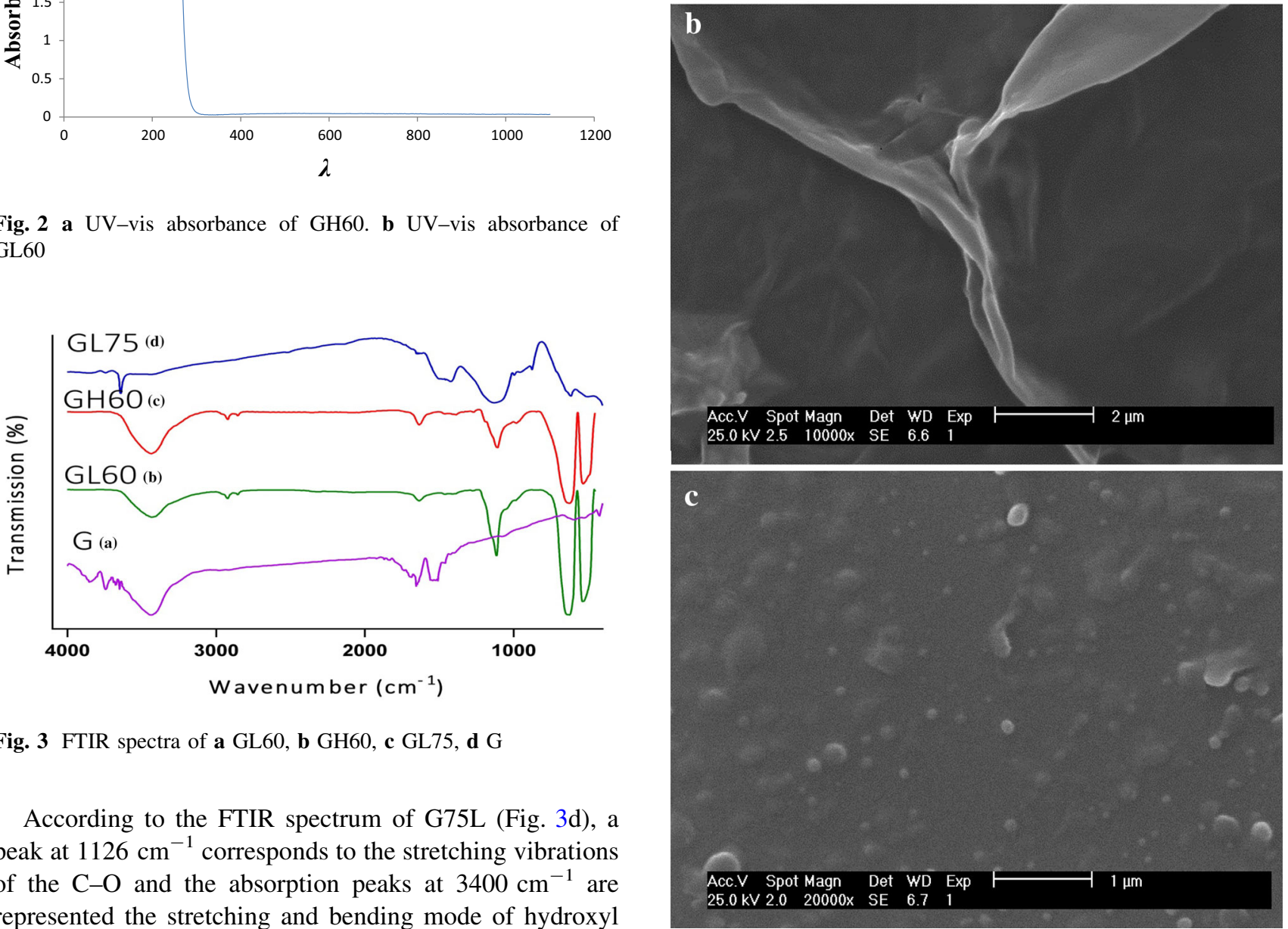

Fig. 3 FTIR spectra of a GL60, b GH60, c GL75, d G

According to the FTIR spectrum of G75L (Fig. 3d), a peak at $1126 \mathrm{~cm}^{-1}$ corresponds to the stretching vibrations of the $\mathrm{C}-\mathrm{O}$ and the absorption peaks at $3400 \mathrm{~cm}^{-1}$ are represented the stretching and bending mode of hydroxyl groups, but peak height has decreased, which indicates a decrease in hydroxyl groups [23]. Lastly, disappearance of carbon-carbon double bonds at $1630 \mathrm{~cm}^{-1}$ along the GL75 sample consequence of strong oxidant such as potassium permanganate $\left(\mathrm{KM}_{\mathrm{n}} \mathrm{O}_{4}\right)$ was observed [22].

SEM images of $\mathrm{G} 60 \mathrm{H}, \mathrm{G} 60 \mathrm{~L}$, and G75L samples (Fig. 4a, b) show their morphology. The graphene planar structure can be observed. However, as it can be seen in Fig. $4 \mathrm{c}$, the graphene plate shape structure is lost. In fact, increasing the temperature has destroyed the plate shape

Fig. 4 a SEM images of GH60. b SEM images of GL60. c SEM images of GL75

structure, deforming it into a defragmented shape similar to carbon black [24].

Raman of the samples was analyzed on a Senterra model of Bruker Company (Germany) with a $785 \mathrm{~nm}$ laser.

Raman spectrum of a typical sample is shown in Fig. 5 consisting of two prominent peaks and a wide band $\left(2600-3200 \mathrm{~cm}^{-1}\right)$. The peak at $1586 \mathrm{~cm}^{-1}$ (G band) is due to 


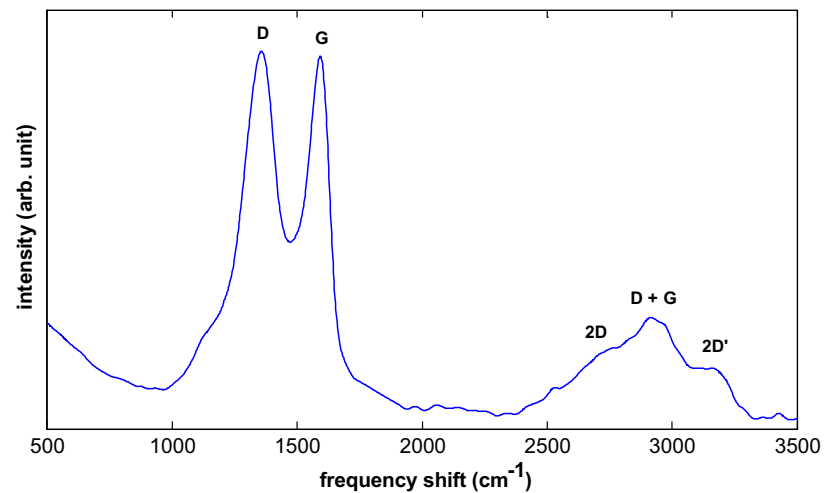

Fig. 5 Raman spectra of G60H

the bond-stretching motion of $\mathrm{sp}^{2}$ hybridized carbon atoms. Structural defects (caused by wrinkles, disruption in the $\mathrm{sp}^{2}$ bonding, or functional groups) contribute to appearance of the peak centered at $1352 \mathrm{~cm}^{-1}$, known as the D band. Generally, intensity of $\mathrm{D}$ peak and weakness $2 \mathrm{D}$ band is the characteristic of graphene nanosheets synthesized using highly oxidizing reagents and a thermal/chemical reduction step [25]. 2D peak of few-layered graphene shifts by the increase in the layers number and its assignment is difficult. [Nanoscale REF] The 2D band of the samples mostly contributes around $2750 \mathrm{~cm}^{-1}$, corresponding to the multilayer graphene (about ten layers).

\section{Conclusion}

The effects of peroxide type, temperature, and reaction time on graphene synthesis process were clarified. The GO was prepared by reaction of graphite with acid and in the existence of oxidant (Hummer's method). XRD and FTIR results showed that GO was created during process. Test results demonstrated that temperature is the most important factor affecting the synthesis process. In fact, high heating temperatures were found to be detrimental for the sheets planar structure.

Open Access This article is distributed under the terms of the Creative Commons Attribution 4.0 International License (http://crea tivecommons.org/licenses/by/4.0/), which permits unrestricted use, distribution, and reproduction in any medium, provided you give appropriate credit to the original author(s) and the source, provide a link to the Creative Commons license, and indicate if changes were made.

\section{References}

1. Novoselov, K.S., Novoselov, K.S.: The rise of graphene. Nat. Mater. 6, 183-191 (2007)

2. Bolotin, K.I., Sikes, K.J., Jiang, Z., Klima, M., Fudenberg, G., Hone, J., Kim, P., Stormer, H.L.: Ultrahigh electron mobility in suspended graphene. Solid State Commun. 146, 351 (2008)
3. Morozov, S.V., Novoselov, K.S., Katsnelson, M.I., Schedin, F., Elias, D.C., Jaszczak, J.A., Geim, A.K.: Giant intrinsic carrier mobilities in graphene and its bilayer. Phys. Rev. Lett. 100, 016602 (2008)

4. Lee, C., Wei, X.D., Kysar, J.W., Hone, J.: Measurement of the elastic properties and intrinsic strength of monolayer graphene. Science 321, 385-388 (2008)

5. Balandin, A.A., Ghosh, S., Bao, W.Z., Calizo, I., Teweldebrhan, D., Miao, F., Lau, C.N.: Superior thermal conductivity of singlelayer graphene. Nano Lett. 8, 902-907 (2008)

6. Nair, R.R., Grigorenko, A.N., Novoselov, K.S., Booth, T.J., Stauber, T., Peres, N.M.R., Geim, A.K.: Fine structure constant defines visual transparency of graphene. Science 320, 1308 (2008)

7. Cai, W., Zhu, Y., Li, X., Piner, R.D., Ruoff, R.S.: Large area fewlayer graphene/graphite films as transparent thin conducting electrodes Appl. Phys. Lett. 95, 123115 (2009)

8. Li, X., Zhu, Y., Cai, W., Borysiak, M., Han, B., Chen, D., Piner, R.D., Colombo, L., Ruoff, R.S.: Transfer of large-area graphene films for high-performance transparent conductive electrodes. Nano Lett. 9, 4359-4363 (2009)

9. Weiss, N.O., Zhou, H., Liao, L., Liu, Y., Jiang, S., Huang, Y., Duan, X.: Graphene: an emerging electronic material. Adv. Mater. 24, 5782-5825 (2012)

10. Huang, C., Li, C., Shi, G.: Graphene based catalysts. Energy Environ. Sci. 5, 8848-8868 (2012)

11. Liu, Y., Dong, X., Chen, P.: Biological and chemical sensors based on graphene materials. Chem. Soc. Rev. 41, 2283-2307 (2012)

12. Sun, Y., Wu, Q., Shi, G.: Graphene based new energy materials. Energy Environ. Sci. 4, 1113-1132 (2011)

13. Wassei, JK., Kaner, RB.: Oh, the places you'll go with graphene. Acc. Chem. Res. (2013). doi:10.1021/ar300184v. Accessed 17 June 2015

14. Nandamuri, G., Roumimov, S., Solanki, R.: Chemical vapor deposition of graphene films. Nanotechnology 21, 145604 (2010)

15. Jiang, D., Schedin, F., Booth, T.J., Khotkevich, V.V., Morozov, S.V., Geim, A.K.: Two-dimensional atomic crystals. Proc. Natl. Acad. Sci. 102, 10451-10453 (2005)

16. Viculis, L.M., Mack, J.J., Mayer, O.M., Hahn, H.T., Kaner, R.B.: Intercalation and exfoliation routes to graphite nanoplatelets. J. Mater. Chem. 15, 974-978 (2005)

17. Segal, M.: Selling graphene by the ton. Nat. Nanotechnol. 4, 612-614 (2009)

18. Niyogi, S., Bekyarova, E., Itkis, M.E., McWilliams, J.L., Hamon, M.A., Haddon, R.C.: Solution properties of graphite and graphene. J. Am. Chem. Soc. 128, 7720-7721 (2006)

19. Hirata, M., Gotou, T., Horiuchi, S., Fujiwara, M., Ohba, M.: Thin-film particles of graphite oxide 1: high-yield synthesis and flexibility of the particles. Carbon 42, 2929-2937 (2004)

20. Yang, H.: Graphene-based supercapacitors for energy storage applications. https://etd.ohiolink.edu/rws_etd/document/get/osu13 76918924/ (2013). Accessed 15 June 2015

21. Russo, C., Stanzione, F., Alfè, M., Ciajolo, A., Tregrossi, A.: Spectral analysis in the UV-visible range for revealing the molecular form of combustion generated carbonaceous species. http://www.combustion-institute.it/proceedings/MCS-7/papers/ PFC/PFC-17.pdf (2011). Accessed 15 June 2015

22. Chen, Ji., Yao, B., Li, C., Shi, G.: An improved Hummers method for eco-friendly synthesis of graphene oxide. Carbon 6, 225-229 (2013)

23. Wah Low, F., Wei Lain, C., Bee Abd Hamid, S.H.: Easy preparation of ultrathin reduced graphene oxide sheets at a high stirring speed. Ceram. Int. 41, 5798-5806 (2015)

24. Bhuyan, M.S.A., Uddin, M.N., Islam, M.M. et al.: Synthesis of graphene. Int. Nano. Lett. 6, 65-83 (2016)

25. Bajpai, R., Roy, S., Kulshrestha, N., Rafiee, J., Koratkarb, N., Misra, D.S.: Graphene supported nickel nanoparticle as a viable replacement for platinum in dye sensitized solar cells. Nanoscale 4, 926-930 (2012) 